\title{
O ENSINO NA ESCOLA DE EDUCAÇÃO FÍSICA DO EXÉRCITO E O CONTEXTO ATUAL JUNTO AO MINISTÉRIO DA EDUCAÇÃO
}

\author{
Instruction at the School of Physical Education of the Army and its present context \\ with the Ministry of Education \\ Ricardo Sá de Assis Carvalho
}

\section{Resumo}

A Lei de Diretrizes e Bases da Educação Nacional (LDBEN), promulgada pela Lei no 9394, de 20 de dezembro de 1996, destinou, à Escola de Educação Física do Exército (EsEFEx), o Art 83 daquela Norma, traduzindo uma carência das prerrogativas plenas a que tem direito, em virtude de sua relevância nacional no campo da Educação Física. Tal Norma, também, é corroborada pelo Parecer no 138 / 2002, do Conselho Nacional de Educação, aprovado em 03 de abril de 2002. Diante de tais assertivas, a EsEFEx reformulou seu Projeto Pedagógico (PP), adequando-se à nova realidade educacional brasileira. O PP da Escola de Educação Física foi consubstanciado perante as premissas básicas de um patamar futuro, não esquecendo o legado daqueles que deixaram o alicerce de uma Instituição reconhecida internacionalmente. Elaborado sob o olhar crítico de todos os integrantes da Escola, de forma a traduzir o trabalho educacional que se pretende realizar, a diretriz para confecção do Projeto Pedagógico seguiu o princípio norteador da educação clara, profunda e abrangente, exeqüível em sua totalidade, objetivando uma formação generalista, humanista e crítica, qualificadora da intervenção acadêmico-profissional, fundamentada no rigor científico, na reflexão filosófica e na conduta ética. Portanto, com intuito de divulgar o desenvolvimento pedagógico da EsEFEx, no século XXI, o presente artigo de divulgação visa apresentar as bases gerais de sua reformulação e as premissas do Ministério da Educação que infletem na adequação dos Cursos.

Palavras-chave: Ministério da Educação, Ensino, Projeto Pedagógico.

\section{Abstract}

The Law of Guidelines and Bases of National Education (LGBNE), promulgated by Law $n^{\circ} 9394$, of 20th of December of 1996, destined Article 83 of that Norm to the School of Physical Education of the Army (EsEFEx), expressing a need for the full prerogatives to which it has the right, in view of its national relevance in the field of Physical Education. This Norm is also corroborated by Report no 138 / 2002, of the National Education Council, approved on 03 of April of 2002. In view of these assertions, EsEFEx reformulated its Pedagogical Project (PP), adjusting it to the new reality of Brazilian education. The PP of the School of Physical Education was consolidated in view of the basic premises of a future platform, not forgetting the legacy of those who have left the foundation of an institution recognized internationally. Elaborated under the critical eye of all integrants of the School, in order to perform the educational work it was intended to realize, the guideline for the confection of the Pedagogical Project followed the principal of clear, profound and ample education, carried out in its totality, aiming for a generalized, humanist and critical formation, qualifier of professional-academic intervention, founded on scientific rigor, on philosophic reflection and ethical conduct. Therefore, with the intention of divulging the pedagogic development of EsEFEx in the XXI century, this disclosing article aims to present the general basis of its re-formulation and the premises of the Ministry of Education that influence the adaptation of the Courses.

Key words: Ministry of Education, Education, Pedagogical Project.

Escola de Educação Física do Exército - Rio de Janeiro - RJ - Brasil.

Recebido em 04.10.2007. Aceito em 25.11.2007.

Revista de Educação Física 2008;140:52-55 


\section{INTRODUÇÃO}

A Escola de Educação Física do Exército (EsEFEx) obteve sua denominação, como Estabelecimento de Ensino, na década de 30, por intermédio do Decreto $\mathrm{Nr}$ 23.252, de 19 de outubro de 1933, como transformação do Centro Militar de Educação Física, anexo à Escola de Sargento de Infantaria, atual quartel do Regimento Escola de Infantaria, sendo transferida para a Fortaleza de São João, na Urca, Rio de Janeiro, no ano de 1930.

Está localizada na majestosa entrada da Baía de Guanabara, no sítio histórico onde Estácio de Sá desembarcou, em 1565, para expulsar os franceses de Villegagnon, lançando, desta forma, os fundamentos da cidade do Rio de Janeiro. A EsEFEx possui em seu currículo, atualmente, a diplomação de 7.662 alunos, distribuídos em distintos cursos, a saber: Curso de Instrutor de Educação Física (2.906 diplomados); Curso de Monitor de Educação Física (4.132); Curso de Medicina Esportiva (147); Curso de Mestre D’Armas (188); Habilitação de Emergência (103); Técnico de Futebol (98) e Massagista (88).

A EsEFEx é um Estabelecimento de Ensino de grau superior e médio, de especialização, da Linha de Ensino Militar Bélico, diretamente subordinado à Diretoria de Pesquisa e Estudos de Pessoal (DPEP), destinado a especializar Oficiais em Educação Física e Desportos e em Educação Física e Esgrima, habilitando-os à ocupação de cargos e ao desempenho de funções previstas nos Quadros de Cargos (QC) e Quadros de Cargos Previstos (QCP) das Organizações Militares (OM), conforme Portaria $\mathrm{Nr}$ 700, de 02 de dezembro 2002, do Comandante do Exército.

Homologada em 1943, pelo Decreto-Lei Nr 5.343, de 25 de março do mesmo ano, que dispunha sobre a habilitação para a direção da educação física em estabelecimentos de ensino de grau secundário, a EsEFEx consubstanciou seu padrão de eficiência, tornando-se símbolo de trabalho honesto e construtivo ao longo destes anos.

Contudo, a evolução do ensino no Brasil e suas prerrogativas diante de um país de dimensões continentais, emergente no esporte mundial, fez com que a Escola imprimisse novo rumo, dentro de seu ímpeto sempre inovador e eficaz.
Pela Lei de Diretrizes e Bases da Educação Nacional (LDBEN), promulgada pela Lei no 9394, de 20 de dezembro de 1996, a Escola de Educação Física do Exército foi abrangida apenas pelo Art 83 daquela Norma, não usufruindo das prerrogativas plenas a que tem direito, em virtude de sua relevância nacional no campo da Educação Física. Também corroborada pelo Parecer no 138 / 2002, do Conselho Nacional de Educação, aprovado em 03 de abril de 2002.

Diante de tais assertivas, coube à EsEFEx a reformulação de seu Projeto Pedagógico, adequando-se à nova realidade brasileira.

\section{PROJETO PEDAGÓGICO DA ESEFEX}

O Projeto Pedagógico da Escola de Educação Física foi elaborado diante das premissas básicas de um patamar futuro, sem deixar para trás o legado daqueles que deixaram o alicerce sólido de uma Instituição reconhecida internacionalmente. Construído sob o olhar crítico de todos os integrantes da Escola, de forma a traduzir o trabalho educacional que se pretende realizar, a diretriz para confecção do Projeto Pedagógico seguiu o princípio norteador da educação clara, profunda e abrangente, exeqüível em sua totalidade, objetivando uma formação generalista, humanista e crítica, qualificadora da intervenção acadêmico-profissional, fundamentada no rigor científico, na reflexão filosófica e na conduta ética.

No aspecto didático, não foi negligenciado o prosseguimento que se pretende dar às formas práticas $\mathrm{e}$ teóricas que exigem qualquer currículo voltado ao campo da Educação Física, principalmente no que tange à pesquisa acadêmica e ao estágio profissional supervisionado, vertentes imprescindíveis na consolidação do saber.

Como base curricular do Curso de Instrutor de Educação Física, foi adotado o regime por módulos, sendo distribuídos em Básico, Avançado e Profissional.

O módulo básico, executado integralmente na Academia Militar das Agulhas Negras, insere, dentro da grade curricular, uma carga horária de 1.635 horas, distribuídas em 1.303 horas na vertente teórica e 332 horas, na prática. Este módulo, formado por disciplinas inerentes ao campo da Educação Física, tais como: psicologia, filosofia, treinamento físico militar, comunicação social, didática, 
estatística, dentre outras, constitui o atributo primordial para formação do especialista militar que desempenhará suas funções em Colégios Militares e em Escolas Militares de formação e especialização.

O módulo Avançado é o passo seguinte, sendo levado a efeito na Escola de Educação Física do Exército, perfazendo um total de 1.488 horas, dentro das mesmas vertentes pedagógicas da prática e da teoria, acrescidas da atividade acadêmico-científico-cultural, consubstanciada nas seguintes disciplinas: Anatomia Humana, Fisiologia do Exercício, Nutrição Desportiva, Psicologia Desportiva, Biomecânica, Administração Desportiva, Orientação, Natação, Tiro, Atletismo, Basquetebol, Esgrima, Futebol, Judô, Pentatlo Militar e Voleibol, juntamente com as disciplinas de desportos coletivos, além de palestras sobre assuntos da atualidade e de estudos avançados em desportos. Dentro deste módulo, também estão inseridas as práticas voltadas para a arbitragem e o acompanhamento das diversas delegações em torneios, como o Guilherme Paraense (Torneio de Tiro da Academia Militar das Agulhas Negras - Resende); NAVAMAER e NAE (competições militares sediadas em sistema de rodízio entre as Escolas de Formação e Preparatórias das três Forças Armadas); Travessia dos Fortes (Maratona Aquática que ocorre, anualmente, no Rio de Janeiro); e Desafio dos Fortes, entre outras de grande destaque. Ressalta-se que, no ano de 2007, a EsEFEx apoiou, ainda, os Jogos Pan-americanos, com seu corpo discente e docente, nas seguintes modalidades: maratona, maratona aquática, triatlo e pentatlo moderno.

Como módulo derradeiro, também efetuado na EsEFEx, encontramos o módulo Profissional, composto pelo Estágio Profissional Curricular. Neste ínterim, a Escola de Educação Física entende que a prática e a teoria caminham de forma paralela, criando a sinergia necessária para consecução e materialização dos objetivos gerais do curso. Sendo assim, o Estágio Supervisionado contempla atividades tais como: execução, como Oficial de Treinamento Físico Militar, do planejamento, da metodologia, da aplicação e da avaliação do Treinamento Físico Militar na Organização Militar a que for designado, sob a orientação de um Oficial licenciado em Educação Física; elaboração de programas de condicionamento físico, com a finalidade de desenvolver, manter e recuperar os Padrões de Desempenho Físico exigidos pela Força
Terrestre, aplicáveis a todos os integrantes de sua Organização Militar (OM); organização de competições desportivas de acordo com as Instruções Gerais 10-39, do Comando do Exército, e normas vigentes das respectivas Confederações Esportivas.

\section{A EQUIVALÊNCIA DO CURSO DE INSTRUTOR À LICENCIATURA}

Destarte, o Comando da Escola de Educação Física do Exército tem envidado esforços para colocar a "Pioneira" em seu devido patamar de excelência metodológica, com intuito de cada vez mais servir ao País e à comunidade desportiva.

Atualmente, encontra-se em estudo, no Ministério da Educação, a nova proposta pedagógica da EsEFEx, por intermédio do Processo no 061111/2006-96, de 06 de outubro de 2006, daquele órgão, onde a Escola argumenta, além do programa oferecido, a sua condição de segunda escola do gênero mais antiga do Brasil, tendo início em 10 de janeiro de 1922 (a mais antiga é a da Polícia Militar de São Paulo), assim como a forma pioneira e multiplicadora em técnicas desportivas e na fundação de novas escolas do gênero (Faculdades de Educação Física).

Não obstante, a EsEFEx tem servido de parâmetro para diversas instituições civis na área de ensino, além de apoiar diversas delegações esportivas, brasileiras e internacionais, em seu intuito maior.

Para fechar este breve relato sobre a EsEFEx e seu modelo pedagógico, deve-se a esta a senda acertada de progresso que, neste setor, desde então, se fez sentir em uma melhor organização das entidades desportivas, em um racional programa de preparação atlética, em um científico controle de treinamento, em uma difusão de centros de formação de especialistas e, principalmente, na criação, ainda que incipiente, de uma mentalidade ginástico-desportiva. No âmbito do ensino, isto é, no círculo dos centros de formação de especialistas que funcionam atualmente no país, várias escolas de educação física são fruto da semente lançada pela EsEFEx. Além disto, no setor educacional, foi a EsEFEx que possibilitou a criação e a organização da Divisão de Educação Física do Ministério da Educação e Saúde, na década de 30.

Sempre como pioneira, foi, também, a EsEFEx a primeira escola de educação física a organizar, anualmente, durante as férias de verão, as colônias de 
férias, contando com um grande público infantil, aplicando os preceitos científicos na prática ginástico-desportiva e divulgando o valor e a importância do esporte para as novas gerações.

\section{REFERÊNCIAS BIBLIOGRÁFICAS}

BRASIL. Decreto-Lei no 1.043, de 21 de outubro de 1969.

BRASIL. Decreto-Lei no 5.343, de 25 de Março de 1943.

BRASIL. Lei no 9.394, de 20 de dezembro de 1996 - Lei de Diretrizes e Bases da Educação Nacional (LDBEN). Diário Oficial da República Federativa do Brasil, 23 de dezembro de 1996.

BRASIL. Lei no 9.696, de 01 de setembro de 1998. Diário Oficial da República Federativa do Brasil, 02 de setembro de 1998.

BRASIL. Lei no 9.786, de 08 de fevereiro de 1999. Diário Oficial da República Federativa do Brasil, 09 de fevereiro de 1999.

\section{Endereço para correspondência:}

Av João Luiz Alves, s/no (Forte São João) - Urca

Rio de Janeiro - RJ - Brasil

CEP: 22291-090

Tel.: 21 2543-3323

\section{ACESSE}

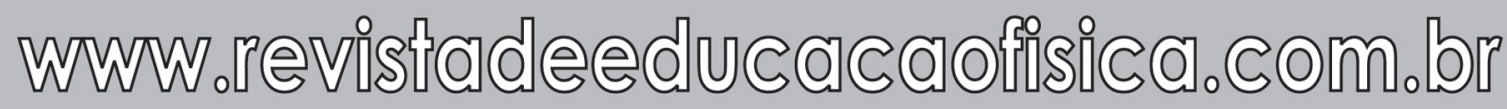

$$
\begin{aligned}
& \text { E LEIA, GRATUITAMENTE, } \\
& \text { TODOS OS ARTIGOS PUBLICADOS, } \\
& \text { DESDE } 1932 .
\end{aligned}
$$
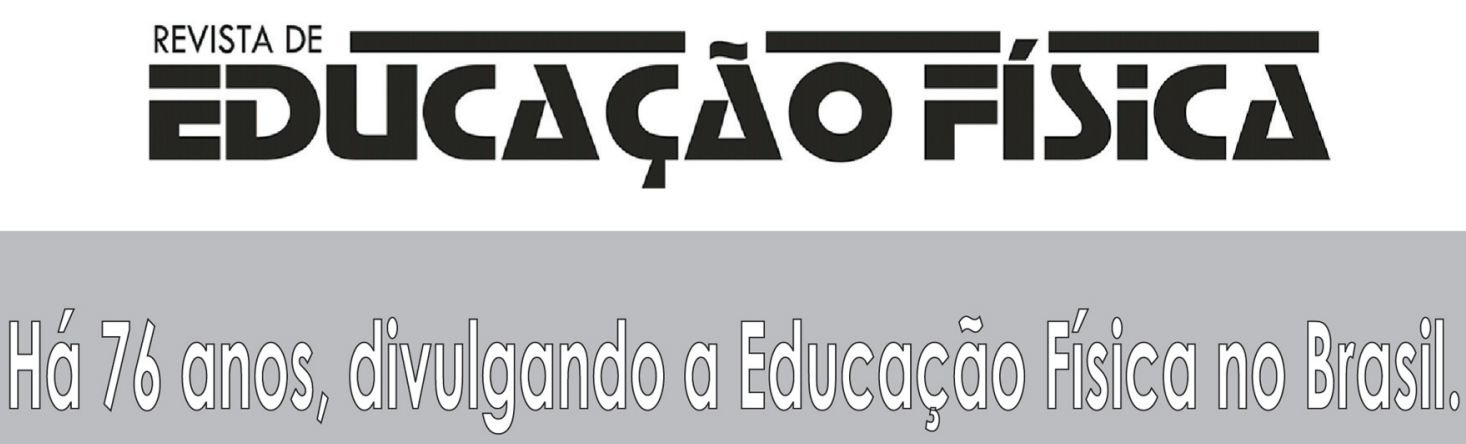